\title{
Extra-axial dural cavernous hemangioma with dural tail sign, masquerading as meningioma
}

Sir,

Cavernous hemangiomas account for $5-13 \%$ of all vascular malformations of the central nervous system..$^{[1]}$ Although most of them occur within the parenchyma, occasional cases have been reported to arise from the dura mater. Majority of the dural cavernous hemangiomas are located in the middle cranial fossa, which are also known as cavernous sinus cavernous hemangiomas. Dural cavernous hemangiomas may sometimes exhibit a dural tail sign; a common radiological feature, if present usually favors meningiomas. Here, we report a case of a large cavernous sinus cavernous hemangioma in an adult male with dural tail radiologically mimicking as meningioma.

A 30-year-old male patient presented with the chief complaints of on and off headache, and right eye ptosis with vertical diplopia since 6 months. No other neurological deficits were noted.

Magnetic resonance imaging showed a large lobulated sellar/suprasellar lesion extending to left temporal fossa extra-axially. Left cavernous sinus was not seen separately, and cavernous part of internal carotid artery was encased. Lesion was hypointense on T1W1 and hyperintense on $\mathrm{T} 2 \mathrm{~W} 1$ and showed intense postcontrast enhancement [Figure 1]. An enhancing dural tail was also noted along sella which was neither enlarged nor destroyed. Sphenoid wing did not show any sclerosis or destruction on computed tomography scan [Figure 2].

Right frontotemporal craniotomy with zygomatic osteotomy and tumor decompression was done. Intraoperatively tumor was firm, nonsuckable, highly vascular, gray-white extending anteriorly up to anterior clinoid space, posteriorly up to right cerebellopontine angle. On histopathology, it showed multiple blood filled spaces at places lined by endothelial cells within the thickened dura separated by loose fibrous septae suggestive of cavernous hemangioma [Figure 3].

Dural cavernous hemangiomas usually present with the symptoms of mass effect such as headache, visual disturbances, and neurological deficits. It is postulated that parenchymal cavernous hemangiomas most likely

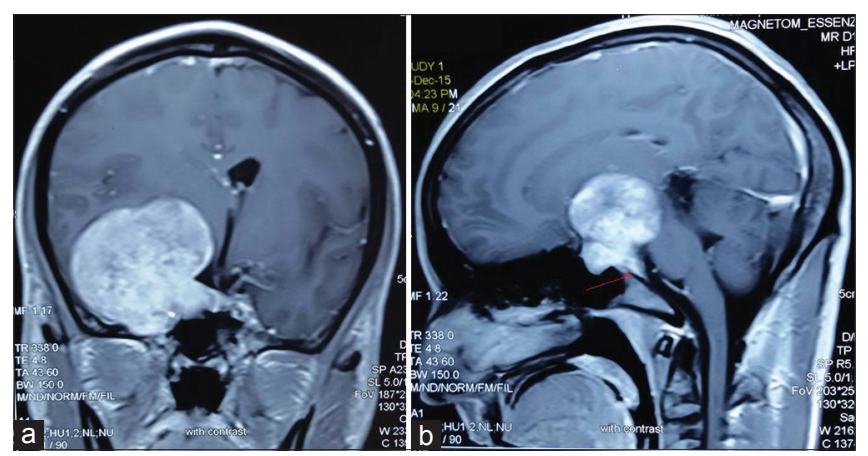

Figure 1: Magnetic resonance imaging scan coronal (a) and sagittal (b) sections showing hyperintensity with contrast enhancement on T2W2 image and a dural tail is well visualized (red arrow)

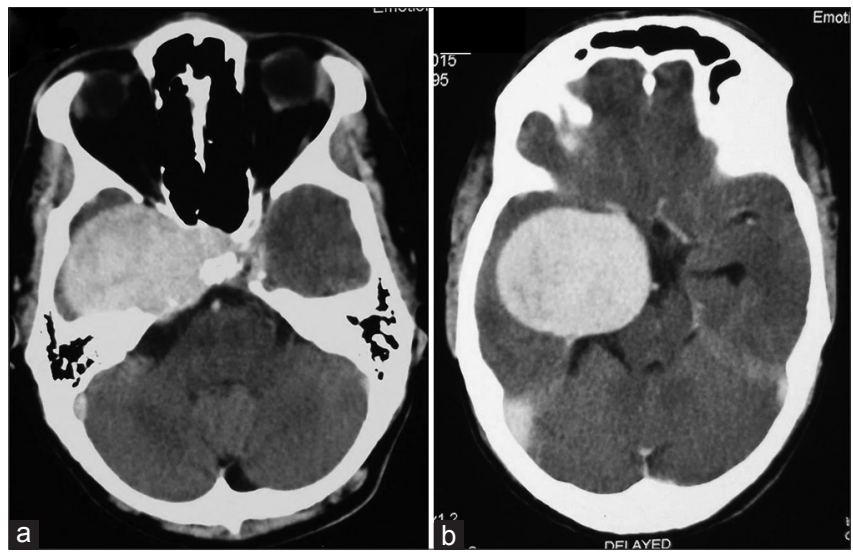

Figure 2: Computed tomography scan images ( $a$ and $b$ ) showing an extra-axial enhancing lesion in the cavernous sinus

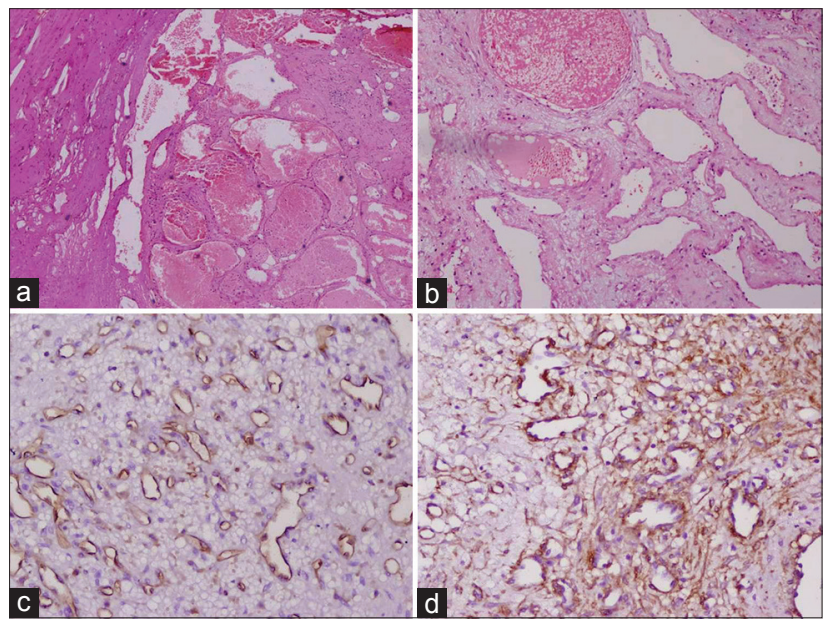

Figure 3: Photomicrographs showing multiple blood-filled spaces within the thickened dura separated by loose fibrous septae. At places, these are lined by flat endothelial lining ( $a$ and $b)$. Immunohistochemistry stain for CD31 (c) and SMA (d) positivity in the endothelial cells of the vascular spaces 
develop due to repeated hemorrhage of any cause. However, pathogenesis of dural-based hemangioma is still not understood. ${ }^{[2]}$ Meyer et al. ${ }^{[3]}$ hypothesized three alternative possible mechanisms for their development which include: (1) Capillary outgrowth at the periphery of the lesion; (2) gradual ectasia of vascular spaces; or (3) thrombosis with organization and progressive sclerosis. Earlier, about twenty cases of the dural-based cavernous sinus cavernous hemangioma have been reported. Few case reports have also described the presence of dural tail which was noted in this case. ${ }^{[4]}$ This dural tail may occur due to meningeal reaction or direct tumor extension which usually leads to the misdiagnosis as meningioma. Furthermore, extreme hyperintensity of hemangioma on T2W2 image is an important clue differentiating it from meningioma. Their complex location and high vascularity may cause profuse intraoperative bleeding and is a great challenge for complete surgical resection. Though intra- and extra-axial hemangiomas are pathologically, a same entity but intraoperative complications and management segregate them as two different and distinct clinical diseases. To conclude, dural-based extra-axial cavernous hemangioma is a rare benign but complex lesion which may delineate dural tail and disguise preoperative diagnosis. A careful radiological diagnosis and angiographic evaluation is very helpful for the operative procedure and results in a better outcome.

\section{Financial support and sponsorship}

Nil.

\section{Conflicts of interest}

There are no conflicts of interest.
Rakesh Kumar Gupta, Ravindra Kumar Saran, Anita Jagetia ${ }^{1}$, Poonam Narang ${ }^{2}$

Departments of Pathology, ${ }^{1}$ Neurosurgery and ${ }^{2}$ Radiodiagnosis, G B Pant Institute of Postgraduate Medical Education and Research, New Delhi, India

Address for correspondence: Dr. Ravindra Kumar Saran, Department of Pathology, G B Pant Institute of Postgraduate Medical Education and Research, New Delhi - 110 002, India. E-mail: ravindraksaran@hotmail.com

\section{References}

1. Del Curling O Jr., Kelly DL Jr., Elster AD, Craven TE. An analysis of the natural history of cavernous angiomas. J Neurosurg 1991;75:702-8.

2. Boockvar JA, Stiefel M, Malhotra N, Dolinskas C, Dwyer-Joyce C, LeRoux PD. Dural cavernous angioma of the posterior sagittal sinus: Case report. Surg Neurol 2005;63:178-81.

3. Meyer FB, Lombardi D, Scheithauer B, Nichols DA. Extra-axial cavernous hemangiomas involving the dural sinuses. J Neurosurg 1990;73:187-92.

4. Wang X, Liu JP, You C, Mao Q. Convexity dural cavernous haemangioma mimicking meningioma: A case report. Br J Neurosurg 2015:1-3.

This is an open access article distributed under the terms of the Creative Commons Attribution-NonCommercial-ShareAlike 3.0 License, which allows others to remix, tweak, and build upon the work non-commercially, as long as the author is credited and the new creations are licensed under the identical terms.

\begin{tabular}{|l|l|}
\hline \multicolumn{2}{|c|}{ Access this article online } \\
\hline Quick Response Code: & Website: \\
\hline & www.ruralneuropractice.com \\
\cline { 2 - 2 } & \\
\hline
\end{tabular}

How to cite this article: Gupta RK, Saran RK, Jagetia A, Narang P. Extra-axial dural cavernous hemangioma with dural tail sign, masquerading as meningioma. J Neurosci Rural Pract 2016;7:615-6. 